\title{
Effect of Light Intensities on Growth Performance of Tetrapleura tetraptera Seedlings Schum. (Thonn.)
}

\section{${ }^{* 1}$ AYENI, O.D; ${ }^{1}$ ONILUDE, QA ; ${ }^{2}$ ADEKOLA, PJ; ${ }^{1}$ AWOSUSI, BM; ${ }^{1}$ MBA, NC; ${ }^{1}$ OGOLIEGBUNE, U; ${ }^{1}$ OKUMODI, BO; ${ }^{1}$ AUDU, MA'}

\author{
${ }^{1}$ Forestry Research Institute of Nigeria, PMB 5054, Jericho Hill, Ibadan, Oyo State, Nigeria \\ ${ }^{2}$ Federal College of Forestry, Jericho Ibadan.P.M.B. 5087, Jericho, Ibadan, Oyo State, Nigeria \\ *Corresponding email: ayeniolatunji62@yahoo.com; Tel: +2348036673441
}

\begin{abstract}
The study assessed the effect of varying light intensities and optimum percentage of sunlight favourable for raising Tetrapleura tetraptera seedlings. The light intensity was measured through photometer. The experiment was subjected to a control without wire mesh(T1) and three other treatments (T2, T3 and T4) covered with different layers of black wire mesh with $99.5 \%, 75 \%, 49.8 \%$ and $25 \%$ light intensities respectively. Each of the treatments was replicated six times in a completely randomized design. The plant height, leaf production and stem diameter were all monitored for 12 weeks. Analysis of Variance (ANOVA) was employed and the means separated using Least Significant Difference (LSD). The results showed that the significance effect $\left(\mathrm{P}=\alpha_{0.05}\right)$ was only observed in the seedlings height of Tetrapleuratetrapteraseedlings. However, the mean values obtained for all the parameters considered revealed the treatment 1(i.e. $99.8 \%$ wire mesh) was observed to be the best performing treatment. For the plant height, mean value ranged between $13.09 \mathrm{~cm}$ and $16.8 \mathrm{~cm}$, a range from $0.22 \mathrm{~cm}$ to $0.28 \mathrm{~mm}$ was recorded for stem girth while the mean values between 22 and 27 were obtained for number of leaves among the treatments. It may be concluded from the study, that light intensity of $100 \%$ i.e without interference should be used for the growth and development as well as production of Tetrapleura tetraptera seedlings in the nursery.
\end{abstract}

\section{DOI:https://dx.doi.org/10.4314/jasem.v25i1.13}

Copyright: Copyright $($ C 2021Ayeni et al. This is an open access article distributed under the Creative Commons Attribution License (CCL), which permits unrestricted use, distribution, and reproduction in any medium, provided the original work is properly cited.

Dates: Received: 02 October 2020; Revised: 26 November 2020; Accepted: 12 December 2020

Keywords: Growth development, light intensities, Tetraplura tetreptera seedlings, wire mesh size

Forest is the art and science of tree resources, including plantations and natural stands. The main goal of forestry is to create and implement systems that allow forest to contribute a sustainable provision of environmental supplies and services. The challenge of forestry is to create ecosystems that are socially accepted while sustaining the resources and any other resources that might be affected. Forest ecosystems have emerged as a vital field of science, applied art technology. (Fahey, 2005). Tetrapleura tetreptera is a deciduous; it reaches $20-25 \mathrm{~m}$ in height, with a girth of $1.5-3 \mathrm{~m}$. The bole is slender and older trees have very small bole, low sharp buttresses. In the forest, the crown is fairly small, thin and rough becoming flat when old, but it tends to spread when in the open. Bark fairly smooth, grey-brown, and very thin: slash reddish, strong smelling, fairly thick. Twigs and young foliage virtually glabrous, minutely hairy, flowers are pinkish-cream turning to orange and are crowded in spike like racemes $5 \mathrm{~cm}-20 \mathrm{~cm}$ long, usually in pairs in the upper leaf axils (Adewunmi, 2002). Tetrapleura tetraptera belongs to the family Fabaceae and it is a species of flowering plants in the pea family native to West Africa. The trees have many uses; its sweet fragrance is highly valued. Its fruits are used to spice dishes and its bark is used for medicinal purposes. Its pods and barks are used for fractured bones, anticonvulsant, gonorrhea, fever, asthma, cough, rheumatism, infertility, insomnia, bilharzias, preservatives and malaria (John and Clement, 2004). Light effect if properly conducted on Tetrapleura seedlings will result in the accurate precision of quantity and quality needed by this plant, hence the result of this research will help to determine the optimum light intensity required for the growth and development of these species at early stage. An overview of some of the key aspects of light will have to be conducted, in particular how much the amount of light is influenced by latitude, the time of day, cloudiness, and then a bit about diffuse and direct radiation. Before the overview it might worth taking a step back and asking 'what is the function of light in forestry? What does light provide?Light is obviously our key energy source. We usually focus on its role in further detail. However solar radiation is also vital for heating up the soil and providing energy for processes such as evaporation. Other important effects of light include: Phototropism: The direction from which the 
light comes can affect the direction in which plants grow. Photoperiodism: Changes in daylength (i.e. the time between sunrise and sunset) and the associated changes in the ratio of red light to far red light, can affect the developmental responses of trees.Mutagenesis: Some forms of solar radiation such as ultra-violet light, can have a negative effect on trees by causing genetic mutations. So when we are talking about light there are additional effects beyond the direct photosynthesis effect.All solar radiation comes from the sun, which has an average surface temperature of about $5,500^{\circ} \mathrm{C}$ and it is the temperature that determines many of the characteristics of solar radiation. At a distance of 150 million kilometers the amount of radiation that we receive at the surface of the atmosphere closest to the sun (termed the solar constant) is about 1,370 watts $/ \mathrm{m}^{2}$. That is 1,370 Joules of energy arriving every second per $\mathrm{m}^{2}$ if we then assume that we are close to the equator and it is a cloud free day about $13 \%$ of that solar radiation may be absorbed by the atmosphere and $13 \%$ scattered. Hence the direct radiation that we received at the Earth's the level of the radiation at the surface of the atmosphere. The maximum amount of solar energy on the Earth's surface is therefore about 1,000 joules per $\mathrm{m}^{2}$ per second. (Paul, 2009). Presently there is high demand for plantation establishment of our indigenous tree species due to indiscriminate deforestation which leads to extinction of some vital tree species. On the other hand the role tree serves to mankind includes amelioration of global warming, time of diseases etc. one of the ways this could be achieved is to study the adaptability of plant species under different level of exposition to sunlight.As a result of this, there is need to carry out research on the light factor and effect of light on this plant for its proper growth and development so as to know the percentage of light required for the mass production (Muteeba, 2000). Therefore, success or failure of growth and development of Tetrapleura tetreptera lies in nursery techniques applied in raising the seedlings and the quantity and quality of light intensity on the crop plant. Therefore, the main objective is to investigate the effect of varying light intensities on the growth of Tetrapleura tetraptera seedlings.

\section{MATERIALS AND METHODS}

Study site: The experiment was carried out in the screen or glass house within the premises of Federal College of Forestry, Ibadan, Oyo State. The College is situated at Jericho in Ibadan North West Local Government area on latitude $7^{\circ} 9^{\prime} \mathrm{N}$ and longitude $3^{\circ} 54^{\prime} \mathrm{E}$. It has annual rainfall of about $1300 \mathrm{~mm}$ $1500 \mathrm{~mm}$ while the annual temperature is $26^{\circ} \mathrm{C}$ and the average relative humidity is about $80-85 \%$ (FRIN Metrological report, 2016). The materials used included; $1 \mathrm{~mm}$ synthetic black wire mesh, germination box for planting seeds, vernier caliper for measuring plant diameter, calibrated ruler in $\mathrm{cm}$ for measuring plant height, field book, chlorophyll meter for examining chlorophyll content, oven, pods of Tetrapleura tetreptera (Plates 1-4) photometer for measuring light intensity. The pods were collected from the National Horticultural Research Institute (NIHORT), Idi-ishin, Ibadan. The seeds were extracted from pod manually by using stone to break the pod in order to extract the seeds. The polythene pots were obtained from Institute of Agricultural Research and Training, (IAR\&T) Moor Plantation, Ibadan. The acid for breaking the seed's dormancy was collected from the seed store of Forestry Research Institute of Nigeria, Ibadan. Photometer was obtained from I.I.T.A. Ibadan.

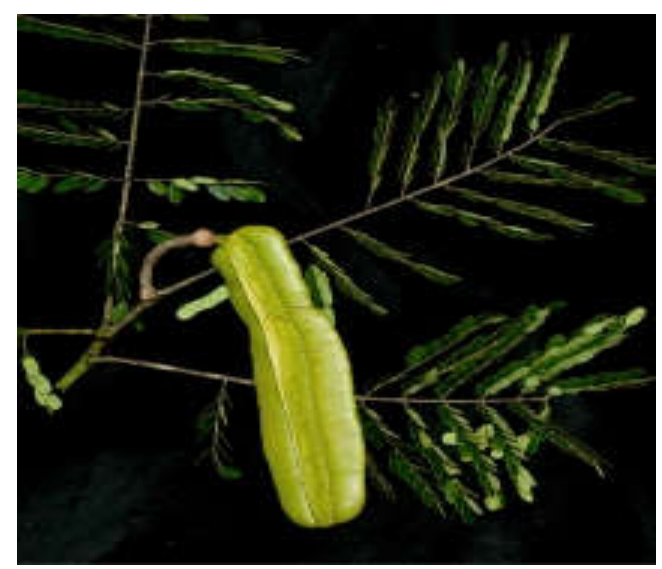

Plate 1: The Fruit of Tetrapleura tetrepteraS. (Thonn.)

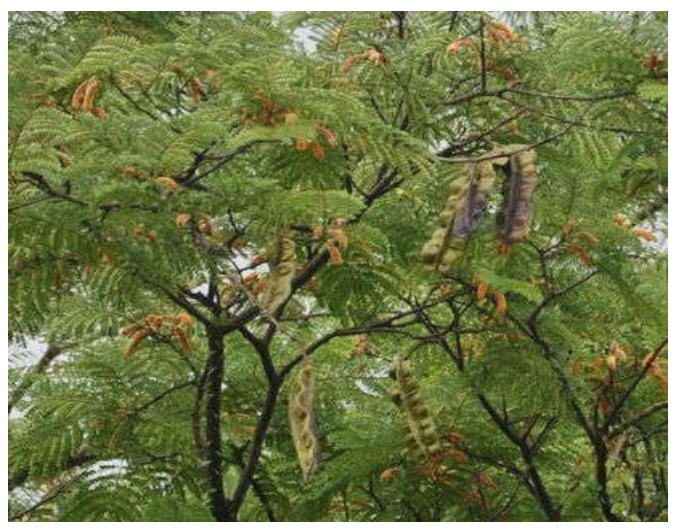

Plate 2: The tree of Tetrapleura tetreptera S. (Thonn.)

Methods of preparation:Sterilized river sand was filed into germination tray to raise the seeds. The seeds were watered on alternate day and prickled out carefully after germination. Polythene pots of $20 \mathrm{~cm}$ by $10 \mathrm{~cm}$ were filled with $1 \mathrm{~kg}$ of topsoil (Loamy) and left for two (2) weeks to gain stability. 

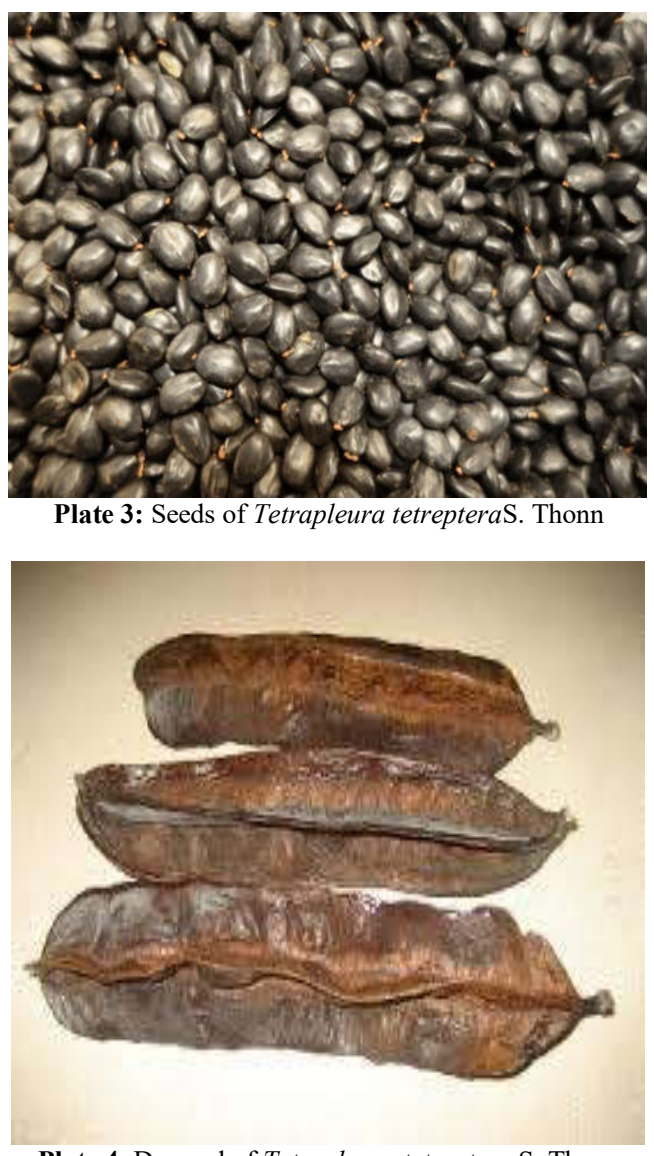

Plate 4: Dry pod of Tetrapleura tetreptera S. Thonn

The germination seeds were then transplanted into the sixteen (16) polythene pots under four treatments. One treatment was placed in a wooden box of size $45 \mathrm{~cm} \mathrm{x}$ $45 \mathrm{~cm}$ by height of $60 \mathrm{~cm}$ in the open for full day for $100 \%$ sun penetration while the remaining treatments were placed under different layers of black wire mesh in the order of one layer, two layers and three layers of black wire mesh in order to vary the light penetration. Photometer was then used to measure the quality of light in each screen house. The treatments were watered in the morning and evening everyday growth parameters were then measured at a specific day in the week for twelve weeks.

Parameters Assessed: The following growth parameters were assessed during the experiment at interval of one week.

Height: measurement was carried out with the aid of a graduated ruler $(\mathrm{cm})$ form the soil level (base of the plant) to the apex of the plant.

Stem diameter: this was done with the aid of vernier caliper and it was measured from below the base plant.
Leaf production:this was done manually by counting the number of leaves on individual plant.

Experimental Design and Layout:The experimental design used was Completely Randomized Design (CRD). The various treatment combinations used in this study included: $\mathrm{T}_{1}$ - Control $(99.8 \% \mathrm{Mesh}) ; \mathrm{T}_{2}-$ (75\% mesh); $\mathrm{T}_{3^{-}}(49.8 \%$ mesh $) ; \mathrm{T}_{4^{-}}(25 \%$ mesh $)$. There were four (4) treatments in this study and each treatment was replicated six (6) times. Watering of plants was done and monitored daily. Growthassessment commenced two weeks after treatment application. Seedling height, stem diameter, leaf production and leaf areawere recorded at two weeks interval for twelve (12) weeks.

Data Collection and Analysis: Growth data was collected on the height, stem diameter and number of leaves. The data were analyzed using Analysis of Variance (ANOVA) in CRD to identify significant difference between the effects of each of the treatments on the growth variable assessed. Where significant, means were separated using Least Significant Difference (LSD).

\section{RESULTS AND DISCUSSION}

Table 1 shows the results of the mean effect of all the treatments on the growth characteristics of Tetrapleura tetraptera seedlings. For the period of assessment, control treatment (treatment 1) recorded the highest mean value among the treatments with 16.8 $\pm 1.14 \mathrm{~cm}$ (Table 1) and percentage mean value $28.05 \%$ (Figure 1) for the seedling height. Seedlings treated with $75 \%$ (Treatment 2) recorded the second highest seedling height with an average mean of 15.9+ $2.11 \mathrm{~cm}$ (Table 1) and percentage mean value of $26.55 \%$ (Figure 1).

The lowest mean value $(13.09 \pm 1.78 \mathrm{~cm})$ was observed in treatment $4(25 \%$ wire mesh $)$ with percentage mean value of $21.86 \%$ (Figure 1). Warner and Zandstra (2004) and Mekonnen and Betewulign (2014) reported similar results to the findings in this study. The result of the analysis of variance (ANOVA) for the effects of the treatment on Tetrapleura tetraptera seedling height is presented in Table 3. There was significant difference $(\mathrm{P}<0.05)$ observed in the seedling height among the treatments (Table 3). The results indicated that varying light intensities for the growth of Tetrapleura tetraptera seedlings have significant effect on the seedling height of Tetrapleura tetraptera. This is also similar to results of study reported by Ologundudu et al. 2013 in their study of effect of light stress on germination and growth parameters of Delonixregia 
Table 1: Mean effects of different treatments on the growth of Tetrapleuratetraptera seedlings

\begin{tabular}{|c|c|c|c|}
\hline Treatment & Tree height $(\mathrm{cm})$ & Leaf production & Collar diameter(mm) \\
\hline T1 & $16.8 \pm 1.14^{\mathrm{a}}$ & $27 \pm 1.89^{\mathrm{a}}$ & $0.28 \pm 0.03^{\mathrm{a}}$ \\
\hline $\mathrm{T} 2$ & $15.9+2.11^{\mathrm{c}}$ & $26+2.11^{\mathrm{a}}$ & $0.26+0.02^{\mathrm{a}}$ \\
\hline $\mathrm{T} 3$ & $14.1 \pm 1.57^{\mathrm{c}}$ & $24 \pm 1.44^{\mathrm{a}}$ & $0.25 \pm 0.02^{\mathrm{a}}$ \\
\hline $\mathrm{T} 4$ & $13.09+1.78^{b}$ & $22+2.23^{\mathrm{a}}$ & $0.22+0.03^{\mathrm{a}}$ \\
\hline
\end{tabular}

Note: Means with the same alphabet are not significantly different, T1- 99.7\%, T2-75\%, T3-49.8\%, T4 - 25\%

Table 2: Showing the values of chlorophyll contents of each sample

\begin{tabular}{lll}
\hline S/N & Sample Description & Chlorophyll Contents $(\boldsymbol{\mu M})$ \\
\hline 1 & T1 (leaves from open nursery) & 0.763 \\
2 & T2 (leaves exposed to $75 \%$ light intensity) & 0.523 \\
3 & T3 (leaves exposed to 49.8\% light intensity) & 0.325 \\
4 & T4 (leaves exposed to 25\% light intensity) & 0.286 \\
\hline & Source: Department of Pharmaceutical Chemistry, University of Ibadan
\end{tabular}

Also, the results of the mean effect of all the treatments on stem girth of Tetrapleura tetraptera seedlings are presented on table 1. 99.7\% wire mesh (Treatment 1) had the highest mean value of $0.28 \pm 0.03 \mathrm{~cm}$ (Table 1$)$ and percentage mean value of $28.0 \%$ (Figure 2 ) for the stem girth. This was followed closely by seedlings treated $75 \%$ wire mesh (Treatment 2)with an average mean of $0.26 \pm 0.02 \mathrm{~cm}$ (Table 1) and percentage mean value of $26.2 \%$ (Figure 2 ) while the least mean value was observed in treatment $4(25 \%$ wire mesh) with mean value of $0.22 \pm 0.03 \mathrm{~cm}$ (Table 1) and percentage mean value of $21.3 \%$ (Figure 2). The result of ANOVA indicated that there was no significant difference $(\mathrm{P}<0.05)$ among the treatments on the stem girth (Table 3 ). The results indicated that the varying light intensities for the growth of Tetrapleura tetraptera have no significant effect on the diameter growth of Tetrapleura tetraptera seedlings. This result however, is in line with the report by Ayeni, (2005) on the diameter growth and yield response of Persia americana, aswas not significant under varying light intensity. Table 1 presents the results of the mean effect of all the treatments on the number of leaves produced by Tetrapleura tetraptera seedlings. Treatment 1 (99.7\% wire mesh) had the highest mean value at the end of the assessment with an average mean of $27 \pm 1.89$ (Table 1) and percentage mean value of $26.0 \%$ (Figure 3), this was followed closely by seedlings treated with $75 \%$ wire mesh (Treatment 2 ) with an average mean of $26 \pm 2.11$ and percentage mean value of $25 \%$ while the least mean value was observed in treatment 4 (25\% wire mesh) with mean value of $22 \pm 2.23$. According to result of ANOVA there was no significant difference at $5 \%$ level of probability $(\mathrm{P}<0.05)$ on the number of leaves produced (Table 4). The results indicated that the varying light intensities do not have significant effect on the number of leaves produced by Tetrapleura tetraptera seedlings. This result however, is not in line with the result reported by Ayeni, (2005) on the number of leaves produced by Persia americana, under varying light intensities. As Persia Americana was reported as significant under varying light intensity. Moreover, the result of the study was corroborated by the result of chlorophyll content presented in table 2. During plant exposure to sunlight, chlorophyll is formed. The study indicated that the more the exposure of plants to sunlight, the more the chlorophyll absorbed and formed.Hence, the development of the growth parameters of Tetrapleura tetraptera seedlings.

Table 3: ANOVA of the effect of different treatments of plant height and stem girth

\begin{tabular}{|c|c|c|c|c|c|c|c|c|c|c|c|}
\hline & & Plant heig & & & & & Stem g & & & & \\
\hline SV & DF & SS & MS & $\mathbf{F}$ & $\operatorname{Pr}(>\mathbf{F})$ & Rem. & SS & MS & $\mathbf{F}$ & $\operatorname{Pr}(>\mathbf{F})$ & Rem. \\
\hline Treatment & 3 & 70.9657 & 23.6552 & 11.05 & 0.000 & $\mathrm{~S}$ & 0.0043 & 0.0014 & 2.33 & 0.0610 & Ns \\
\hline Error & 20 & 42.8348 & 2.1417 & & & & 0.0112 & 0.0006 & & & \\
\hline Total & 23 & 123.8005 & & & & & 0.0155 & & & & \\
\hline
\end{tabular}

Table 4: ANOVA of the effect of different treatment on the leaves production (Count)

\begin{tabular}{llllll}
\hline \multicolumn{5}{c}{ Number of leaves } \\
\hline SV & SS & DF & MS & F & P-value \\
\hline Treatment & 22.0000 & 3 & 7.3000 & 2.16 & $0.0625 \mathrm{Ns}$ \\
Error & 67.5000 & 20 & 3.375 & & \\
Total & 89.5000 & 23 & & & \\
\hline \multicolumn{4}{c}{ Note: Ns- Non - Significant at 5\% level of probability $(\alpha$ oos }
\end{tabular}

Note: Ns- Non - Significant at $5 \%$ level of probability $\left(\alpha_{0.05}\right)$

Conclusion: For optimum growth of Tetrapleura tetraptera seedlings in the nursery, $100 \%$ light intensity or open space without light interference on the seedlings is recommended because it has the 
highest mean values in the study.It is therefore confirmed that the exposure of this seedling to sunlight is an effective silvicultural method for raising the seedlings of Tetrapleura tetraptera and for hastening its growth in girth and leaf production, while treatment two had the highest height. It can thrive very well in area with open canopy and an area with slightly closed canopy will can guarantee $75 \%$ light penetration.

\section{REFERENCES}

Adewunmi, O. A, (2002): Drugs research and production.O.A.U J. Experimental Botany. 51 350-150.

Ayeni, O.D., (2005): Effect of varying light intensities on the growth of Avocado (Perseaamericana) seedlings. Unpublished Paper submitted to the department of Forestry Technology Pg. 15-18.

Fahey, J.W (2005): Moringa oleifera: A review of the Medicinal Evidence for its Nutritional, Therapeutic and Prophylactic Properties. Trees life J. 1:5

FRIN (2018). Forestry Research Institute of Nigeria, Meteorological Report.

John, A.O, and Clement O. Adewunmi, (2004). Antiinflammatory and hypoglycaemic effects of Tetrapleura tetraptera (Taub) [Fabaceae] fruit aqueous extract in rats. J. Ethnopharmacology, 95 (2-3). 177-182.
Mekonnen, T. and Betewulign, E. (2014).Elucidating the role of different mulching materials on the growth performance of Hot Pepper (Capsicum annum).Inter. J. Agri. Res. 9(6): 284-293.

Muteeba, T. (2000): An assessment of regeneration potentials of Entandrophragma angolense in the exploited areas of mangrove forest reserve, Kalangala District. Bsc. Project report submitted to the Faculty of Forestry and Natural Conservation, Makerere University, Kampala, Uganda 81pp.

Ologundudu, F, Adelusi, A.A; Adekoya, K.P (2013). Effect of light stress on germination and growth parameters of corchorus olitorius, Celosia argentea, Amaranthus cruentus, Abelmoschus esculentus and Delonix regia. Notulae Scientia Biologicae 5(4): 468-475.

Warner, J: Zandstra, J (2004).Biodegradable polymer mulches in bell pepper production. pp15https://www.ridgetownc.com/research/documen ts/zandstra pepper degradable mulch harrow 0 4. PDF 